\title{
Asesmen Penalaran Inch
}

\author{
Try Susanti \\ Jurusan Pendidikan Biologi, Fakultas Tarbiyah dan Keguruan \\ IAIN Sulthan Thaha Saifuddin Jambi, Indonesia \\ E-mail: trysusantidarma@yahoo.co.id \\ Hp. 085263001711
}

\begin{abstract}
The article aims to describe Inch reasoning which becomes a process to collect the evidences consciously and to relate between knowledge and experience in order to explain what has been seen, thought, and concluded. Thus, critical thinking becomes one of reasoning types. It is also a process for someone to answer difficult questions which cannot be answered in time rationally. There were eight functions that cannot be separated each other and become the indicators of critical thinking. They are Question at issue, Purpose, Information, Concepts, Assumptions, Points of View, Interpretation and inference, Implication and consequences. Therefore, it is suggested for science teacher to understand the Inch reasoning which can be implemented in their assessment.
\end{abstract}

Key Words: Assessment, Inch Reasoning, Primer Feedback, Critical Thinking, Science

\begin{abstract}
Abstrak: Artikel ini bertujuan untuk menggambarkan asesmen penalaran yang merupakan suatu kegiatan pengumpulan bukti yang dilakukan secara sengaja untuk membuat hubungan antara pengalaman dan pengetahuan agar dapat menjelaskan apa yang dilihat, dipikirkan dan disimpulkan. Berpikir kritis merupakan suatu bentuk penalaran yang merupakan proses pada seseorang yang mencoba menjawab pertanyaan yang sulit yang informasinya tidak ditemukan pada saat itu secara rasional. Terdapat delapan fungsi yang saling berhubungan dan menjadi indikator dalam berpikir kritis yaitu: Question at issue, Purpose, Information, Concepts, Assumptions, Points of View, Interpretation and inference, Implication and consequences. Untuk itu disarankan agar dosen dapat memahami asesmen penalaran Inch dan dapt diaplikasikan di kelasnya.
\end{abstract}

Kata Kunci: Asesmen, Penalaran Inch, Umpan Balik Primer, Berpikir Kritis, Sains

\section{PENDAHULUAN}

Visi asesmen yang digambarkan oleh National Science Education Standards, yaitu asesmen merupakan mekanisme feedback primer dalam sistem pendidikan sains. Sebagai contoh, data asesmen yang diperoleh dari siswa merupakan feedback tentang sebaik apakah siswa dapat mencapai tujuan yang diharapkan guru atau orang tua mereka., feedback dengan guru yaitu sebaik apakah siswa mereka belajar, feedback bagi lembaga yaitu sebaik apakah efektivitas guru dan program yang dijalankan, dan feedback bagi pembuat kebijakan yaitu sebaik apakah kebijakan mereka berjalan. Feedback tersebut menuntun perubahan dalam sistem pendidikan sains dengan menstimulasi perubahan dalam kebijakan, menuntun pengembangan guru yang profesional, dan mendorong siswa untuk memperbaiki pemahaman mereka terhadap sains.
Stiggins (1994) mengemukakan lima kategori target hasil belajar yang layak dijadikan dasar dalam menentukan jenis asesmen yang akan digunakan oleh pengajar, yaitu: pengetahuan (knowledge), Penalaran (reasoning), Kemampuan (skill), produk (product), dan sikap (affective). Adapun teknik asesmen yang dapat digunakan yaitu respon terbatas (selected respon) yang termasuk di dalamnya bentuk tes pilihan ganda, isian singkat, benar-salah, menjodohkan dan melengkapi, uraian (essay) yang merupakan asesmen berupa persoalan kompleks yang menuntut jawaban tertulis berupa paparan solusi permasalahan, kinerja (performance) yang merupakan pengukuran langsung terhadap prestasi yang ditunjukkan siswa selama proses pembelajaran, dan komunikasi pribadi (personal communication) yang menilai prestasi siswa dalam partisipasinya dalam diskusi kelas. 
Penalaran merupakan salah satu target hasil belajar yang dapat dilihat dari bagaimana seseorang berpikir dalam memecahkan setiap pertanyaan, kemampuan bernalar merupakan kemampuan berpikir tingkat tinggi yang tergambar salah satunya melalui berpikir kritis. Untuk mengetahui kemampuan penalaran pada seseorang dapat digunakan berbagai teknik asesmen, baik berupa asesmen tertulis maupun asesmen lisan.

\section{ASESMEN}

Istilah asesmen (assessment) dalam Stiggins (1994) sebagai penilaian proses, kemajuan, dan hasil belajar siswa (outcomes). Sementara itu asesmen diartikan oleh Kumano (2001) sebagai "The process of collecting data which is shows the develompment of learning". Dengan demikian dapat disimpukan bahwa asesmen merupakan istilah yang tepat untuk penilaian proses belajar siswa. Namun, meskipun proses belajar siswa merupakan hal yang penting yang dinilai dalam asesmen, faktor hasil belajar juga tidak dapat dikesampingkan. Asesmen juga merupakan kegiatan pengumpulan bukti yang dilakukan secara sengaja, sistematis, dan berkelanjutan serta digunakan untuk menilai kompetensi siswa.

Menurut NRC dalam Sukaesih (2010) Asesmen merupakan proses penting karena hasilnya dapat digunakan untuk merencanakan pengajaran, memandu belajar peserta didik, menentukan tingkat/urutan, membuat perbedaan, pengembangan teori pendidikan, merumuskan kebijakan, mengalokasikan sumberdaya, dan mengevaluasi kurikulum.

\section{PENALARAN}

Menurut Tim Balai Pustaka (Suratman, 2005), istilah penalaran mengandung tiga pengertian, yaitu:

1. Cara (hal) menggunakan nalar, pemikiran, atau cara berpikir logis.

2. Hal mengembangkan atau mengendalikan sesuatu dengan nalar dan bukan dengan perasaan atau pengalaman.
3. Proses mental dalam mengembangkan pikiran dari beberapa fakta atau prinsip.

Menurut Shurter dan Pierce dalam Yuniarti (2007), istilah penalaran sebagai terjemahan dan reasoning didefinisikan sebagai proses pencapaian kesimpulan logis berdasarkan fakta dan sumber yang relevan.

Keraf (1982) dalam Shadiq (2004) menjelaskan penalaran (jalan pikiran atau reasoning) sebagai "Proses berpikir yang berusaha menghubung-hubungkan fakta-fakta atau evidensi-evidensi yang diketahui menuju kepada suatu kesimpulan". Secara lebih lanjut, Fadjar Shadiq mendefinisikan bahwa penalaran merupakan suatu kegiatan, suatu proses atau suatu aktivitas berfikir untuk menarik kesimpulan atau membuat suatu pernyataan baru yang benar berdasar pada beberapa pernyataan yang kebenarannya telah dibuktikan atau diasumsikan sebelumnya.

Penalaran adalah suatu cara berpikir manusia yang mampu mengaitkan suatu ide dengan pemikiran lain yang tidak hanya ada di biologi tetapi juga dalam ilmu pengetahuan lain dan kehidupan sehari-hari.

Seperti yang diungkapkan oleh Kusumah (Yuniarti, 2007) mengungkapkan bahwa penalaran adalah cara berpikir yang memperlihatkan hubungan antara dua hal atau lebih berdasarkan sifat dan aturan yang telah diakui kebenarannya dengan menggunakan langkah-langkah hingga mencapai suatu kesimpulan.

Penalaran adalah proses kemampuan berpikir seseorang untuk mendapatkan suatu pengetahuan baru dengan cara melogikakan konsep-konsep yang diketahuinya berdasarkan bukti-bukti yang ada dan mengkontradiksikannya dengan pengetahuan yang sebelumnya. Penalaran juga merupakan semua hubungan antara pengalaman dan pengetahuan yang digunakan seseorang untuk menjelaskan apa yang dilihat, dipikirkan dan disimpulkan. Penalaran berasal dari kemampuan berpikir seseorang.

Penalaran dalam biologi dapat mengembangkan dan mengungkap pandangan seseorang 
tentang suatu permasalahan. Seorang yang nalarnya tinggi memungkinkan akan mempunyai persepsi yang berbeda terhadap suatu permasalahan bila dibandingkan dengan seorang yang nalarnya rendah.

\section{ASESMEN PENALARAN}

Asesmen penalaran adalah kegiatan pengumpulan bukti yang dilakukan secara sengaja untuk membuat hubungan antara pengalaman dan pengetahuan agar dapat menjelaskan apa yang dilihat, dipikirkan dan disimpulkan. Salah satu bentuk dari penalaran adalah kemampuan berpikir dengan kritis. Berpikir kritis adalah sebuah proses pada seseorang yang mencoba menjawab pertanyaan yang sulit yang informasinya tidak ditemukan pada saat itu secara rasional. Berpikir kritis memerlukan pertimbangan yang menurut Joanne Kurfiss (Inch, Warnick \& Endres, 2006) adalah sebagai berikut:

An Investigation whose purpose is to explore a situasion, phenomenon, question, or problem to arrive at a hypothesis or conclusion about it that integrates all availble information and that therefore can be convicingly justified.

Jadi, merupakan sebuah penyelidikan yang bertujuan untuk mengeksplorasi situasi, fenomena, pertanyaan atau masalah untuk menyusun hipotesis atau konklusi, yang memadukan semua informasi yang dimungkinkan dan dapat diyakini keberannya.

Dengan berpikir kritis seseorang akan mampu mengarahkan pemikirannya sesuai dengan yang diinginkannya, dapat bertanggung jawab terhadap kehidupannya sendiri dan memperbaiki kehidupannya tanpa dipengaruhi oleh pengaruh-pengaruh dari luar yang bisa berakibat buruk. Seseorang yang mampu berpikir kritis akan dapat melontarkan pertanyaan-pertanyaan yang tepat, mengumpulkan berbagai informasi yang dibutuhkan, mampu secara efisien dan kreatif memilahmilah informasi dan berpikir logis hingga sampai pada kesimpulan dan keputusan yang dapat dipercaya dan dapat dipertanggung jawabkan. Sebagaimana yang dikemukakan oleh Inch, et al. (2006) bahwa orang yang berpikir kritis mengenai sebuah masalah tidak akan menetap pada solusi yang sudah ada, tetapi akan menunda penilaian sambil mencari semua alasan, fakta yang relevan yang akan menghasilkan perbuatan keputusan yang baik.

Dalam hal ini konsep-konsep yang diberikan bisa menjadi salah satu masukan informasi yang dibutuhkannya. Namun bila tidak mampu berpikir kritis konsep-konsep yang diberikan hanya akan berhenti sampai pada suatu bentuk ajaran saja tanpa tahu bagaimana menggunakan informasi itu dan mengaplikasikannya dalam kehidupan sehari-hari.

Richard Paul dan Linda Elder (Inch, et al. 2006) menyarankan bahwa berpikir kritis bisa dibagi kedalam delapan fungsi yang saling berkaitan, yang ditunjukkan dalam tabel 1 . Masing-masing fungsi menggambarkan sebuah fungsi yang penting dari hasil dan keseluruhan kualitas berpikir.

Adapun kedelapan fungsi yang saling berhubungan dan menjadi indikator dalam berpikir kritis adalah sebagai berikut:

1. Question at issue. Pertanyaan mengenai issue ini hanya rangsangan untuk berpikir kritis. Pertanyaannya mengidentifikasi sebuah masalah yang perlu diselesaikan.

2. Purpose. Tujuan menggambarkan hasil yang diinginkan oleh seseorang. Apa yang diharapkan untuk dicapai.

3. Information. Informasi bisa dalam berbagai bentuk termasuk data statistik, laporan dari para saksi mata, pengamatan individu atau hal lain dari sumber lain yang bisa membantu seseorang menjawab pertanyaan. Informasi memberikan isi dari pikiran yang diambil untuk mengembangkan pikiran dan menyusun pikiran baru.

4. Concepts. Konsep adalah teori, defenisi, aturan dan hukum yang membangun pikiran dan perbuatan seseorang.

5. Assumptions. Asumsi adalah dugaan atau pandangan sebelumnya yang diterima 
yang dianggap benar. Asumsi mewakili dasar pemikiran.

6. Points of View. Sudut pandang datang dari latar belakang individu, pemikiran, pengalaman, dan sikap. Orang-orang beralasan, dan berpikir dari sudut pandang yang berbeda. Bagian dari pemikiran kritis melibatkan proses interpretasi dan memahami sudut pandang orang lain.

7. Interpretation and inference. Ketika berpikir seseorang mencampur informasi dan pemikiran kedalam sudut pandang, konsep dan pandangan yang sudah ada. Dari campuran ini seseorang mempertanyakan, memeriksa, meneliti dan menginterpretasi serta menarik kesimpulan.

8. Implication and consequences. Alasan dan pemikiran seseorang akan membawa implikasi dan konsekuensi. Jika seseorang bertahan pada kesimpulan yang diambil, apa yang akan terjadi? Jika seseorang mengubah sikap dan keyakinannya, efek apa yang akan terjadi pada keputusan masa depan yang mungkin diambil?
Pada waktu berpikir, mengembangkan ide-ide, dan menyatakan pendapat merupakan hal penting bagi siswa untuk secara aktif dapat menjawab pertanyaan dengan pemikiran yang kritis dan direncanakan. Beberapa hal yang harus diperhatikan pada saat berpikir kritis, yaitu: menyaring generalisasi dan menghindari penyederhanaan, memunculkan dan menilai solusi terhadap masalah-masalah, membandingkan perspektif, interpretasi, atau teori-teori, membaca secara kritis dan mencari informasi yang tidak sesuai dengan perspektif kita, mendengarkan secara kritis, dan secara serius mempertimbangkan pandangan-pandangan yang tidak sesuai (Inch, et al., 2006).

\section{INTRUMEN BERFIKIR KRITIS INCH}

\begin{tabular}{|c|c|c|c|}
\hline No & $\begin{array}{c}\text { Fungsi } \\
\text { Berpikir Kritis }\end{array}$ & $\begin{array}{c}\text { Indikator } \\
\text { Berpikir Kritis }\end{array}$ & Soal \\
\hline 1. & $\begin{array}{l}\text { Question at } \\
\text { issue } \\
\text { (Mempertanyak } \\
\text { an masalah) }\end{array}$ & $\begin{array}{l}\text { - Membuat } \\
\text { pertanyaan } \\
\text { berdasarkan } \\
\text { fenomena atau } \\
\text { data }\end{array}$ & $\begin{array}{l}\text { Kultur jaringan adalah suatu metode untuk } \\
\text { mengisolasi bagian dari tanaman seperti sekelompok } \\
\text { sel atau jaringan yang ditumbuhkan dengan kondisi } \\
\text { aseptik, sehingga bagian tanaman tersebut dapat } \\
\text { memperbanyak diri tumbuh menjadi tanaman } \\
\text { lengkap kembali. } \\
\text { Teknik kultur jaringan memanfaatkan prinsip } \\
\text { perbanyakan tumbuhan secara vegetatif. Berbeda } \\
\text { dari teknik perbanyakan tumbuhan secara } \\
\text { konvensional, teknik kultur jaringan dilakukan } \\
\text { dalam kondisi aseptik di dalam botol kultur dengan } \\
\text { medium dan kondisi tertentu. Karena itu teknik ini } \\
\text { sering kali disebut kultur in vitro. Dikatakan in vitro } \\
\text { (bahasa Latin), berarti "di dalam kaca" karena } \\
\text { jaringan tersebut dibiakkan di dalam botol kultur } \\
\text { dengan medium dan kondisi tertentu. Teori dasar } \\
\text { dari kultur in vitro ini adalah Totipotensi. Teori ini } \\
\text { mempercayai bahwa setiap bagian tanaman dapat }\end{array}$ \\
\hline
\end{tabular}




\begin{tabular}{|c|c|c|c|}
\hline & & & $\begin{array}{l}\text { berkembang biak karena seluruh bagian tanaman } \\
\text { terdiri atas jaringan-jaringan hidup. Oleh karena itu, } \\
\text { semua organisme baru yang berhasil ditumbuhkan } \\
\text { akan memiliki sifat yang sama persis dengan } \\
\text { induknya. } \\
\text { Pertanyaan manakah yang tepat terkait data di atas? } \\
\text { a. Sebutkan beberapa contoh tanaman yang dapat } \\
\text { di perbanyak dengan teknik kultur jaringan? } \\
\text { b. Apakah yang dimaksud dengan teori } \\
\text { totipotensi? } \\
\text { c. Apakah kelemahan dari teknik kultur jaringan? } \\
\text { d. Siapakah yang pertama kali menemukan teknik } \\
\text { kultur jaringan? }\end{array}$ \\
\hline 2. & $\begin{array}{l}\text { Information } \\
\text { (Informasi) }\end{array}$ & $\begin{array}{l}\text { - } \text { Mendeskripsika } \\
\text { n sesuatu } \\
\text { berdasarkan } \\
\text { data atau } \\
\text { informasi } \\
\text { - } \text { Merumuskan } \\
\text { sesuatu } \\
\text { berdasarkan } \\
\text { informasi yang } \\
\text { tersedia }\end{array}$ & $\begin{array}{l}\text { Apakah yang dimaksud dengan teknik kultur } \\
\text { jaringan? }\end{array}$ \\
\hline 3. & $\begin{array}{l}\text { Purpose } \\
\text { (Tujuan) }\end{array}$ & $\begin{array}{l}\text { - Merumuskan } \\
\text { tujuan } \\
\text { - Mendeskripsika } \\
\mathrm{n} \\
\text { fungsi/manfaat/ } \\
\text { peranan sesuatu }\end{array}$ & $\begin{array}{l}\text { Tumbuhan monokotil seperti palem-paleman sering } \\
\text { dijadikan tanaman penghijauan di pinggir jalan, } \\
\text { karena... } \\
\text { a. memiliki banyak daun sebagai tempat berteduh } \\
\text { b. tidak memiliki akar utama sehingga tidak } \\
\text { merusak jalan } \\
\text { c. memiliki bentuk yang indah sebagai tanaman hias } \\
\text { d. daunnya tidak mudah gugur sehingga tidak } \\
\text { mengotori jalan }\end{array}$ \\
\hline 4. & $\begin{array}{l}\text { Concepts } \\
\text { (Konsep) }\end{array}$ & $\begin{array}{l}\text { - Menjelaskan } \\
\text { konsep } \\
\text { - Menerapkan } \\
\text { konsep }\end{array}$ & $\begin{array}{l}\text { Jelaskan minimal empat ciri yang membedakan } \\
\text { antara tumbuhan dikotil dengan monokotil! }\end{array}$ \\
\hline 5. & $\begin{array}{l}\text { Assumptions } \\
\text { (Asumsi) }\end{array}$ & $\begin{array}{l}\text { - Membuat } \\
\text { asumsi }\end{array}$ & $\begin{array}{l}\text { Mengapa Cyanophyta (Algae hijau biru) tidak } \\
\text { digolongkan kedalam kingdom protista? } \\
\text { a. Tidak memiliki klorofil } \\
\text { b. Tidak memiliki membran inti } \\
\text { c. Tidak memiliki membran sel } \\
\text { d. Tidak memiliki plastida }\end{array}$ \\
\hline 6. & $\begin{array}{l}\text { Points of View } \\
\text { (Sudut pandang) }\end{array}$ & $\begin{array}{l}\text { - Membuat sudut } \\
\text { pandang } \\
\text { terhadap }\end{array}$ & $\begin{array}{l}\text { Luas hutan di Indonesia semakin berkurang, dan } \\
\text { laju kerusakan hutan } \pm 3,8 \text { juta hektar per tahun } \\
\text { pada periode } 1997-2000 \text {. Berdasarkan sudut }\end{array}$ \\
\hline
\end{tabular}




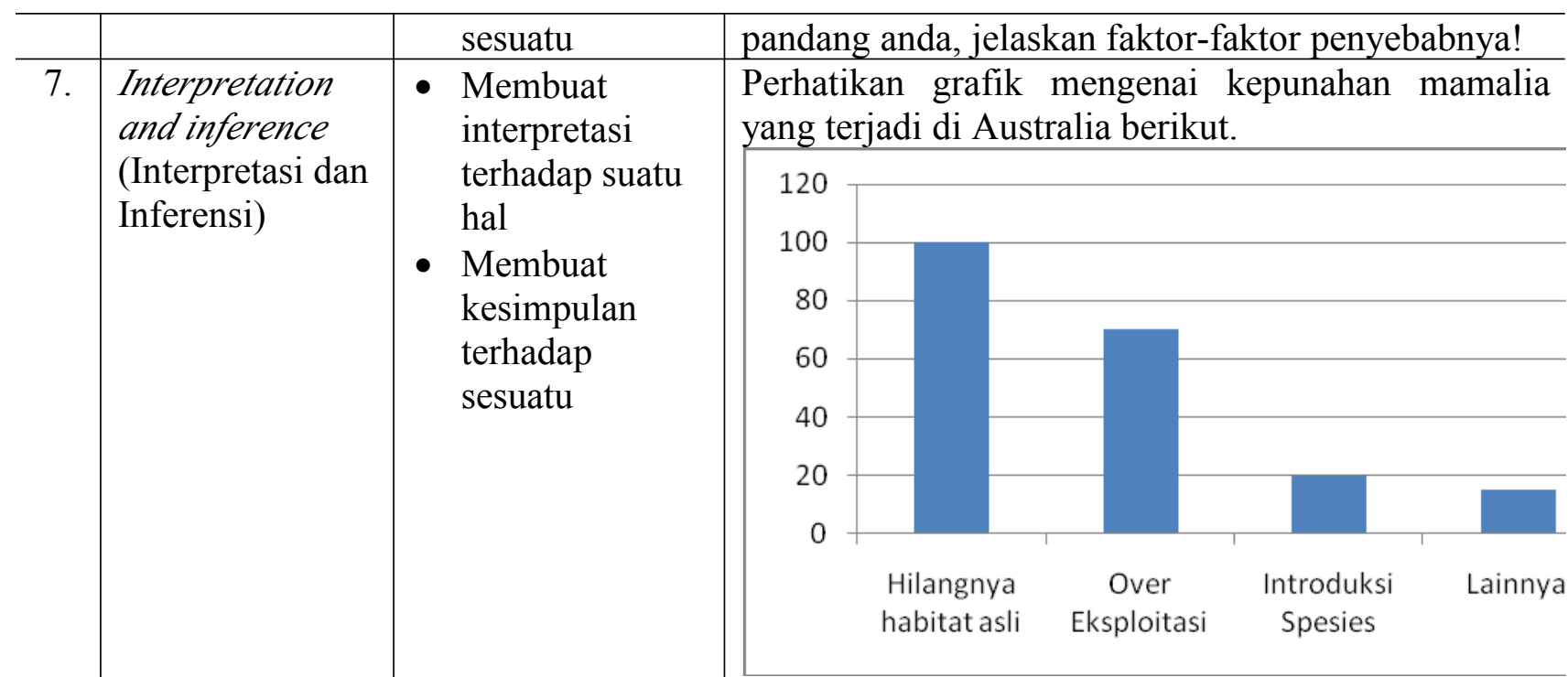

Apa yang dapat anda simpulkan dari grafik di atas?

a. Eksploitasi yang berlebihan menjadi faktor punahnya mamalia di Australia

b. Ada tiga penyebab punahnya mamalia yaitu hilangnya habitat asli, eksploitasi besarbesaran, dan introduksi spesies

c. Habitat alami amat penting untuk kelangsungan dan kelestarian hidup mamalia

d. Faktor lain merupakan penyebab terbesar dari punahnya mamalia di Australia

8. Implication and $\bullet$ Menjelaskan $\quad$ Sistem pertanian yang diterapkan saat ini dapat concequences implikasi dan (Implikasi dan akibat dari mengancam keanekaragaman hayati yang ada di bumi. Berikut ini data di lapangan yang mendukung pernyataan di atas, kecuali...

a. Penggunaan pestisida dapat mematikan organisme yang bukan hama

b. Limbah pertanian menjadi polutan yang berbahaya bagi organisme di perairan

c. Lahan persawahan menjadi miskin nutrien karena terus menerus ditanami

d. Menanam berbagai jenis tanaman rentan dengan hama endemik perusak tanaman. pertanyaan yang sulit yang informasinya tidak

\section{SIMPULAN}

Berdasarkan uraian di atas, Asesmen penalaran adalah kegiatan pengumpulan bukti yang dilakukan secara sengaja untuk membuat hubungan antara pengalaman dan pengetahuan agar dapat menjelaskan apa yang dilihat, dipikirkan dan disimpulkan. Salah satu bentuk dari penalaran adalah kemampuan berpikir dengan kritis. Berpikir kritis adalah sebuah proses pada seseorang yang mencoba menjawab ditemukan pada saat itu secara rasional.

Adapun kedelapan fungsi yang saling berhubungan dan menjadi indikator dalam berpikir kritis adalah sebagai berikut: Question at issue adalah pertanyaannya mengidentifikasi sebuah masalah yang perlu diselesaikan. Purpose (tujuan) adalah untuk menggambarkan hasil yang diinginkan oleh seseorang. Apa yang diharapkan untuk dicapai. Information 
(Informasi) bisa dalam berbagai bentuk termasuk data statistik, laporan dari para saksi mata, pengamatan individu atau hal lain dari sumber lain yang bisa membantu seseorang menjawab pertanyaan. Concepts adalah teori, defenisi, aturan dan hukum yang membangun pikiran dan perbuatan seseorang. Assumptions.

Asumsi adalah dugaan atau pandangan sebelumnya yang diterima yang dianggap benar. Points of View adalah Sudut pandang dartang dari latar belakang individu, pemikiran, pengalaman, dan sikap. Orang-orang beralasan, dan berpikir dari sudut pandang yang berbeda. Interpretation and inference berhubungan dengan situasi dimana ketika berpikir seseorang mencampur informasi dan pemikiran kedalam sudut pandang, konsep dan pandangan yang sudah ada. Implication and consequences merupakan alasan dan pemikiran seseorang akan membawa implikasi dan konsekuensi.

\section{DAFTAR RUJUKAN}

Inch, E. S., Warnick, B \& Endres, D. 2006. Critical Thinking and Communication: The Use of Reason in Argument. Boston: Allyn and Bacon.
Shadiq, F. 2004. Pemecahan Masalah, Penalaran dan Komunikasi. Disampaikan pada Diklat Instruktur/ Pengembang Matematika SMA Jenjang Dasar Tanggal 6 s.d. 19 Agustus 2004 di PPPG Matematika. Yogyakarta: Departemen Pendidikan Nasional Direktorat Jenderal Pendidikan Dasar dan Menengah Pusat Pengembangan Penataran Guru (PPPG) Matematika Yogyakarta.

Sukaesih, S. 2010. Pembelajaran Berbasis Praktikum dengan Menerapkan Asesmen Tes Lisan Pada Topik Keanekaragaman Hayati untuk Mengembangkan KemamIpuan Berpikir Kritis dan Sikap Ilmiah Mahasiswa. Tesis UPI. Tidak diterbitkan.

Stiggins, R. J. 1994. Educational tests and measurements; Examinations. United States New York and Toronto and New York. Xxvii+477p.

Yuniarti, Y. 2007. "Meningkatkan Kemampuan Penalaran dan Komunikasi Matematis Siswa SMP melalui Pembelajaran dengan Pendekatan Inkuiri". Tesis. UPI. Tidak diterbitkan. 